\title{
Developing a Remote Laboratory for Heat Transfer Studies
}

\author{
http://dx.doi.org/10.3991/ijim.v9i2.4368 \\ R. Ennetta and I. Nasri \\ Higher Institute of Industrial Systems of Gabes, University of Gabes, \\ Salaheddine El Ayoubi Street, 6011, Gabes, Tunisia.
}

\begin{abstract}
Remote labs that enable students to conduct real-world experiments at a distance using a computer and Web-based tools can be the only realistic method of performing practical experiments in the context of distance learning.

The e-Sience Tempus project, "Maghreb Network of remote labs," offers an innovative pedagogical approach that integrates eLearning and is complementary to classroom learning. The main objective of this project is to create an efficient remote labs network in the Maghreb region for the modernization of higher education in technological sciences.

The current paper summarizes the work carried out on a heat exchanger bench to be fully accessed and controlled remotely. Through this new device a student of Mechanical Engineering is introduced to many fundamental aspects of heat transfer.
\end{abstract}

Index Terms-e-Sience project; heat exchanger; Maghreb; remote lab;

\section{INTRODUCTION}

The Web has spurred our imagination as to how education can be radically transformed and enhanced through the adoption of ICT. While the use of Web-based education to date has seen as a significant innovation, it has not had the revolutionary impact originally envisioned and has certainly not displaced the traditional settings of classrooms, schools, colleges and universities [1], especially in educational laboratories. Those practical educational aspects need more and more development.

As we know, the use of laboratory experiments is a critically important aspect of education. Experience in teaching has shown that a complementary approach combining theoretical and practical exercises is vital for effective learning [2]. According to Hansen (1990) [3], students retain $25 \%$ of what they listen to, $45 \%$ of what they listen to and see, and $70 \%$ when they manipulate, control and modify experiments, putting into practice what they are learning.

In the context of distance learning, remote access to distance laboratories can be the only realistic method of performing practical experiments [2]. These remote labs enable students to conduct real-world experiments at a distance using a computer and Web-based tools [4].

Increasingly, teaching institutions are offering remote access to distant laboratories as part of an overall eLearning strategy. Remote experimentation provided as part of a Web-based learning approach affords a number of critical benefits, allowing flexible access to on-campus resources free of time or geographical constraints. However, adapting and redeveloping existing experimental resources for this purpose is a very hard task.

In the Maghreb region, the strong demand for top technicians and engineers needs an increased training capacity. Enrollment growth and quality of courses are often incompatible.

To avoid typical constraints of traditional laboratories such as scheduling as well as cost of equipment and location, remote operation of real plants can be incorporated into engineering courses [5].

The e-Sience Tempus project, "Maghreb Network of remote labs," [6] offers an innovative pedagogical approach that integrates eLearning and is complementary to classroom learning. The main objective of this project is to create an efficient remote labs network in the Maghreb region for the modernization of higher education in technological sciences.

As a partner of this project, we had to adapt and develop distant access solutions for two remote labs to allow students to perform practical experiments on heat transfer and mechanical vibration. These two remote labs will be a part of the Maghreb Network of remote labs.

In this paper, a heat exchanger experiment remote lab is presented, through which a student of Mechanical Engineering is introduced, in both theoretical and practical ways, to many fundamental aspects of heat transfer. We present the work carried out to adapt and redesign this device to be fully accessed from the Internet.

\section{THE E-SIENCE PROJECT}

The main objectives of this project were

- to build a network of remote labs in the Maghreb region

- to implement of a state-of-the-art solution

- to establish a best practice for the modernization of higher education in technological sciences.

This remote labs network will enable students to conduct real-world experiments at a distance and to assess the educational potential of such a system.

The specific objectives of this project are

- Adaptation of content to the technological changes in sciences while taking into account the expectations of the market's needs,

- Setting of three remote measurements platforms in the Maghreb region and their networking,

- Implementation of remote practical activities,

- Development of eLearning modules and courses, 
- Evaluation of the developed course,

- Accreditation of the learning units in accordance with the Bologna process,

- Use of resources,

- Dissemination of the project at the national level in partner countries and at international level,

- Sustainability through enrollment in university courses in partner countries.

At this time, the e-Sience project is well advanced and the majority of remote labs are being tested and evaluated.

At the Higher Institute of Industrial Systems of Gabes (ISSIG), as a partner of the e-Sience Tempus project, we adapted and developed distant access solutions for two remote labs to allow students to perform practical experiments on heat transfer and mechanical vibration. These two remote labs are directly accessible through the ISSIG e-Lab server.

The current paper summarizes the work carried out on a heat exchanger bench to be fully accessed and controlled remotely. Through this new device a student of Mechanical Engineering is introduced, in both theoretical and practical ways, to many fundamental aspects of heat transfer.

\section{THE HEAT EXCHANGER BENCH}

Engineers learning about thermodynamics and heat transfer need to know how well different heat exchangers work. They can use this information to decide the correct heat exchanger for their own designs. TD360 Heat Exchanger bench [7] shows students how different smallscale heat exchangers work. They mimic the most common heat exchangers used in industry and compare how well they work for different flow rates and temperatures.

The TD360 module (Fig.1) is a compact frame with two water circuits (hot and cold) and instruments to measure and display water flow and temperature. This module can work with various types of heat exchangers (Concentric Tube Heat Exchanger, Plate Heat Exchanger, Shell and Tube Heat Exchanger and Jacketed Vessel with Coil and Stirrer). Students test each of the optional heat exchangers and record the flow and temperature changes to see how well the heat exchangers work. If they have one or more of the heat exchangers, students can compare them to see which is best for any application.

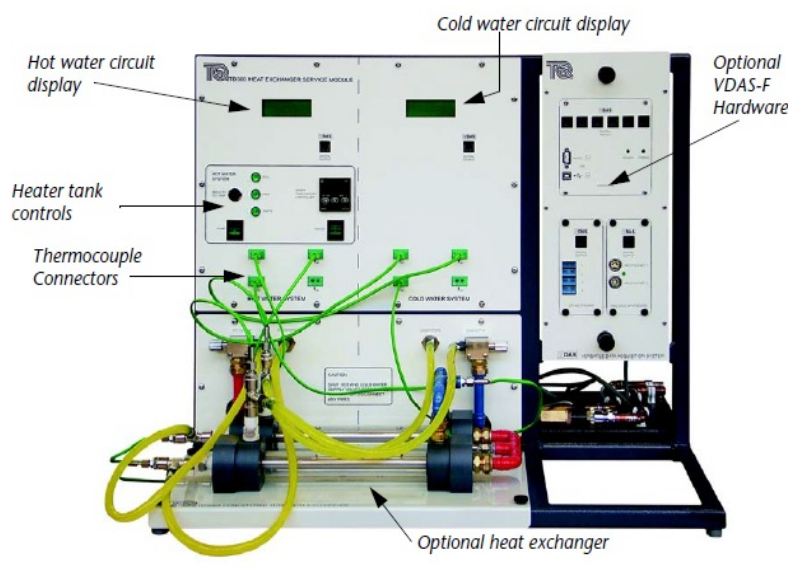

Figure 1. TD360 Heat Exchanger bench
In the present experiment we used only the Concentric Tube Heat Exchanger (Fig. 2). This heat exchanger is a simple shell and tube heat exchanger. It has two tubes, one inside the other. The outer tube is the shell. The inner tube carries the water from the hot circuit; the other tube carries the water from the cold circuit. Heat transfers between the two tubes. You can connect the water circuits to give contra-flow (counter-flow) or parallel flow experiments. This heat exchanger is in two equal parts with extra thermocouples at the mid-point.

These experiments help students understand more clearly how the temperature changes along the heat exchanger.

Fig. 3 shows an example of the results of the effect of varying the cold flow rate on the performance of the heat exchanger in both parallel flow and counter flow connections. In this case the hot flow rate and heater temperature are fixed.

\section{THE REMOTE CONTROLlED HEAT EXCHANGER BENCH}

The architecture of the ISSIG e-Lab is presented in Fig.4. This e-Lab is composed of two remote labs: the mechanical vibration remote lab and the heat exchanger remote lab.

To provide access to these remote labs, we use the MIT iLab Shared Architecture (ISA) [8]. In ISA, the Service Broker is the core of the architecture and provides user authentication, authorization, experiment data storage and access to scheduling services [9].

The heat exchanger bench was adapted for remote operation. The adaptations included control of the hot water supply pump, the heater and the cold and hot water supply flows (Fig. 5). To provide students with an overview of the whole heat exchanger bench, an IP camera was located in the laboratory.

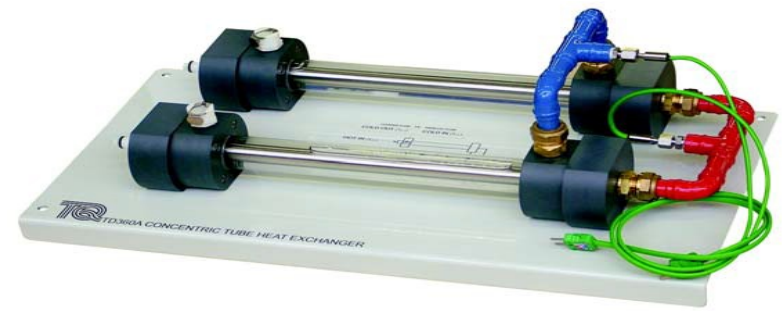

Figure 2. Concentric Tube Heat Exchanger (TD360-a)
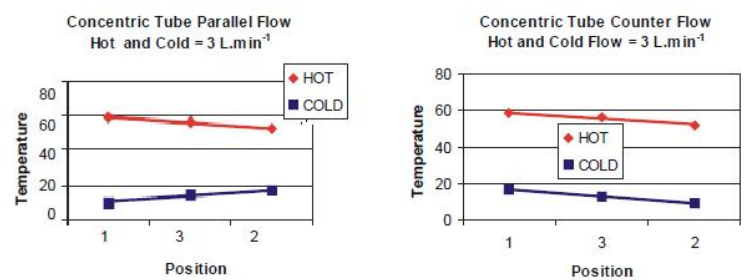

Concentric Tube Parallel Flow Hot $=3$ L.min in $^{-1}$ Cold $=0.5$ L.m in

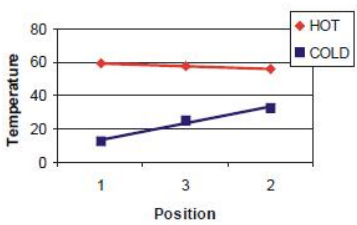

Concentric Tube Counter Flow Hot $=3 \mathrm{Lm}^{-1}, \mathrm{Cold}=0.5 \mathrm{Lmin}^{-1}$

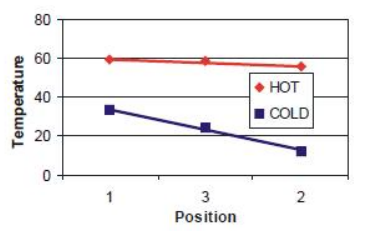

Figure 3. Example of heat exchanger experiment results 


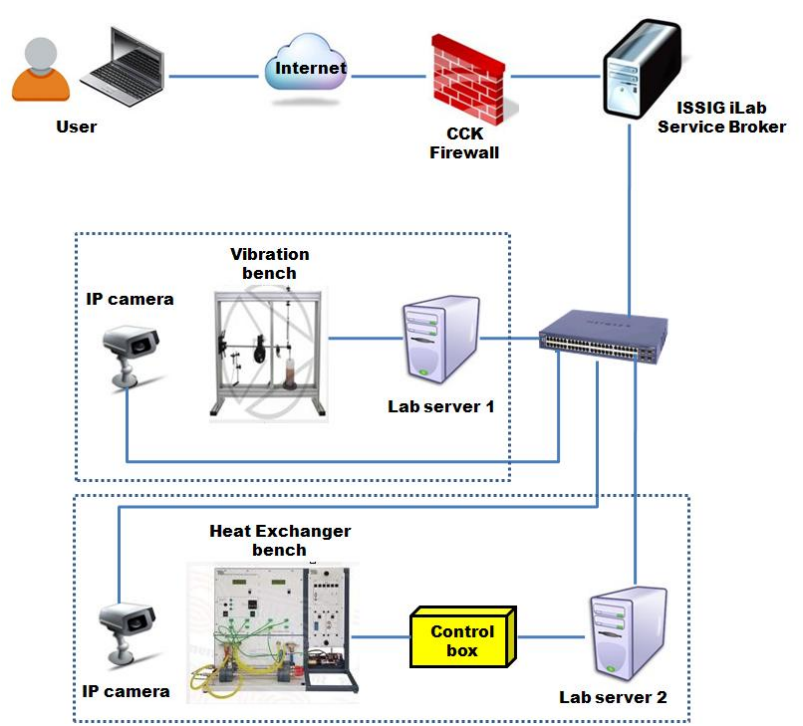

Figure 4. The ISSIG e-Lab architecture.

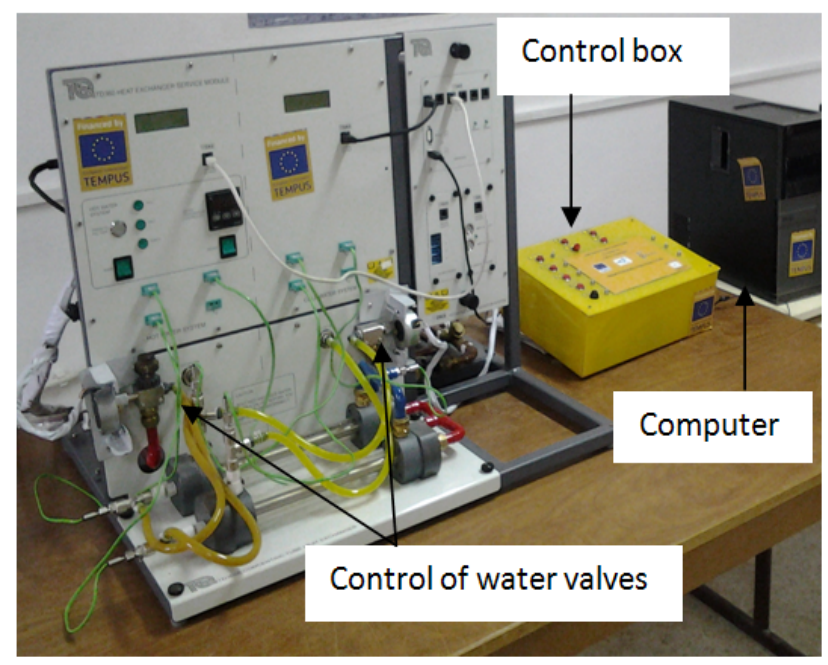

Figure 5. Heat exchanger remote Lab.

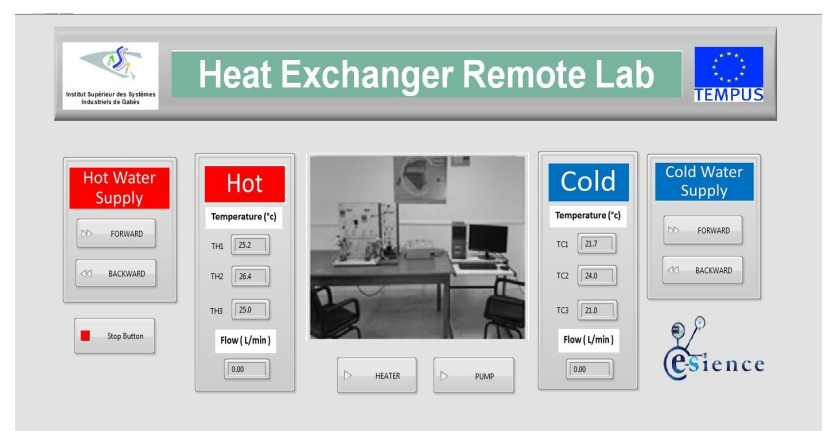

Figure 6. Screenshot of the user interface developed at ISSIG to control the heat exchanger remote lab.

The user interface (UI) application created using Labview software is shown in Fig. 6. This UI was developed to enable students to control the heat exchanger remotely.

The UI included buttons for controlling the different parts of the heat exchanger bench and displayed the feeds from water supply flowmeters, thermocouples and the IP video camera.

\section{Pedagogical eValuation}

The evaluation of our remote labs will be in the framework of the whole evaluation strategy adopted by all e-Sience project partners [10].

The evaluation strategy of the project will focus on five different but interrelated directions: (a) usability of remote labs; (b) learners' attitude toward remote labs; (c) technical evaluation of remote lab operation; (d) evaluation of the eLearning content, namely the teaching units previously described; and (e) the learning outcome.

The evaluation will be conducted in two sequential phases:

- Phase I : pilot evaluation

- Phase II : large scale evaluation

The first phase will be the pilot evaluation of all remote labs in small scale usage. During this phase we plan to assess the remote labs' usability and proper functioning as well as the learners' attitude toward remote labs.

The first evaluation phase of the ISSIG remote labs will be conducted with a population of 30 students who will perform their experiments on every remote lab.

According to the results of the first stage evaluation of the remote labs, the operation and user interface will be improved and they will be deployed for large scale usage. After that period of usage, the large scale evaluation will be conducted. The large scale evaluation will focus on the usability of the remote labs; the learners' attitude toward remote labs; evaluation of the eLearning content; and assessment of the learning outcome [10].

\section{CONCLUSION}

The main objective of e-Sience Tempus project was to create an efficient remote labs network in the Maghreb region. As a partner of this project, ISSIG had to adapt and develop distant access solutions for two remote labs to allow students to perform practical experiments on heat transfer and mechanical vibration.

The current paper presented the work carried out on a heat exchanger bench to be fully accessed and controlled remotely. This includs control of the water supply pump, the heater, and the cold and hot water supply flows. Also, an IP camera was located in the laboratory to provide students with an overview of the whole device.

In addition, a user interface application was developed to enable students to control the heat exchanger remotely. It incorporated buttons for controlling the different parts of the heat exchanger bench and displayed feedback from the sensors (flowmeters and thermocouples) and the IP camera.

To test and validate this remote lab an evaluation phase will be conducted. It will be in the framework of the whole evaluation strategy adopted by all e-Sience project partners.

\section{ACKNOWLEDGMENT}

This project has been funded with support from the European Commission. This publication reflects the views of only the author, and the Commission cannot be held responsible for any use which may be made of the information contained therein. 


\section{SPECIAL FOCUS PAPER}

\section{DEVELOPING A REMOTE LABORATORY FOR HEAT TRANSFER STUDIES}

\section{REFERENCES}

[1] C. Allison, A. Miller, I. Oliver, R. Michaelson and T. Tiropanis, "The Web in education," Computer Networks, vol. 56, pp. 38113824, 2012. http://dx.doi.org/10.1016/j.comnet.2012.09.017

[2] M.J. Callaghan, J. Harkin, T. McGinnity and L.P. Maguire, “An Internet-based methodology for remotely accessed embedded systems," 2002 IEEE International Conference on Systems, Man and Cybernetics, vol. 6, pp. 6-9 October 2002. http://dx.doi.org/10.1109/ICSMC.2002.1175578

[3] E. Hansen, "The role of interactive video technology in higher education: case study and proposed framework", Education Technology, pp. 13-21, 1990.

[4] E. Scanlon, C. Colwell, M. Cooper and T. Di Paolo, "Remote experiments, re-versioning and re-thinking science learning", Computers \& Education, vol. 43, Iss. 1-2, pp. 153-163, AugustSeptember http://dx.doi.org/10.1016/j.compedu.2003.12.010

[5] E. Fabregas, G. Farias, S. Dormido-Canto, S. Dormido, F. Esquembre, "Developing a remote laboratory for engineering education,” Computers \& Education, vol. 57, pp. 1686-1697, 2011. http://dx.doi.org/10.1016/j.compedu.2011.02.015

[6] T. Zimmer, D. Geoffroy, A. Pester, R. Oros, Th. Tsiatsos, S. Douka. "eSience: Setting up a network of remote labs in the magrebian countries," International Conference on Engineering Education and Research (iCEER 2013), Marrakesh, Morocco, pp. 1-5 July, 2013. http://www.esience.org
[7] http://www.tecquipment.com/Thermodynamics/Heat Transfer/TD 360.aspx

[8] http://ilab.mit.edu/wiki, The iLab Project.

[9] D. G. Zutin, M. E. Auer and I. Gustavsson, "A VISIR lab server for the iLab shared architecture," 2011 IEEE Global Engineering Education Conference (EDUCON): Learning Environments and Ecosystems in Engineering Education, pp. 30-33, Amman, Jordan, 4-6 April 2010.

[10] T. Tsiatsos, S. Douka, A. Mavridis, S. Tegos, A. Naddami, T. Zimmer and D. Geoffroy, "Evaluation plan and preliminary evaluation of a network of remote labs in the Maghrebian countries", iJOE International Journal of Online Engineering, Vol. 10, Iss. 5, pp. 15-20, September 2014.

\section{AUTHORS}

R. Ennetta and I. Nasri are with the Mechanical Engineering Department of the Higher Institute of Industrial Systems of Gabes (ISSIG), Gabes University, Salaheddine El Ayoubi Street, 6011 Gabes, Tunisia (e-mail: ridha.ennetta@issig.rnu.tn, ibrahimnasri2013@gmail.com).

This work was supported in part by eSience (rESeau maghrébIn de laboratoirEs à distance) European Project under Tempus IV Program. Project No: 530341-TEMPUS-1-2012-1-FR-TEMPUS-JPCR. Submitted 07 January 2015. Published as resubmitted by the authors 23 March 2015. 